\title{
Pessimism versus Realism
}

Taylor Frank

English for Secondary Education major/Spanish minor

University of Iowa, Iowa City, IA USA

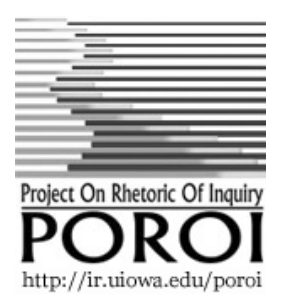

According to Webster's dictionary a pessimist (PES-uh-mist - noun) is

"a person who habitually sees or anticipates the worst or is disposed to be gloomy" or "an adherent of the doctrine of pessimism".

We see pessimism as something negative, something that interferes with the success of the future or the attitudes of others. However, sometimes I think that when it comes to politics, pessimist is synonymous to realism. Realist (ree-uh-list), noun, "a person who tends to view or represent things as they really are".

From an outside perspective, these two words may not seem anything alike. Yet in the current state of our society, looking inwardly at the nation's issues, these two words relate more than they differ. So pessimist? Maybe, but I think that I look at the current state of our nation as well as the next four years of our nation as something that is also very real. I look at the reality of our nation as something that is absolutely terrifying.

Four years ago, our country took a huge step. We made history and, historically, this was a huge milestone for The United States of America. We elected America's first black president. Every presidency in the history of our country has had its struggles and its successes. President Obama was thrown into a pit of a failing U.S. economy, low employment and criticism of daily worldwide issues. While I would like to say that the next four years will shape this country immensely I believe that, realistically, no matter who is put in office we have so much work to put in as a country in order for anything to improve.

We see four years as such a long time, when, realistically, four years will never be sufficient to make a difference in a country requiring so much attention. I understand that this view may be pessimistic, but I challenge American's to look at the big picture. Does one person have the ability to impact four years of time? Truly, I don't know. I think that this country's shape does not rely on a Republican or Democrat but a massive movement of individuals willing to compromise and put themselves second for the bettering of our country. 